minor intrathoracic airways obstruction with predominantly expiratory flow limitation.

It therefore seems unlikely that inspiratory flow limitation is more prone to cause $\mathrm{CO}_{2}$ retention than expiratory obstruction. This suggests that $\mathrm{CO}_{2}$ retention is caused by obstruction to airflow and is independent of the phase of breathing that is predominantly affected.

I would like to thank Miss Judith Turner for help, and my colleagues for allowing me to study patients under their care.
REFERENCES

Bland, J. W., Edwards, F. K., and Brinsfield, D. (1969). American fournal of Cardiology, 23, 830.

Campbell, E. J. M., and Howell, J. B. L. (1962). British Medical fournal, 2, 630.

Clark, T. J. H. (1968). Clinical Science, 34, 559.

Jordanoglou, J., and Pride, N. B. (1968). Thorax, 23, 38

Macklem, P. T., Fraser, R. G., and Brown, W. G. (1965). fournal of Clinical Investigation, 44, 897.

McNeill, R. S., Malcolm, G. D., and Brown, W. R. (1959). Thorax, 14, 225. Milic-Emili, J., and Tyler, J. M. (1963). Fournal of Applied Physiology, 18, 497.

Miller, R. D., and Hyatt, R. E. (1969). Mayo Clinic Proceedings, 44, 145.

Nairn, J. R., and McNeill, R. S. (1963). British Medical fournal, 1, 1321.

Saunders, K. B. (1967). British Medical fournal, 2, 399.

Tandon, M. K., and Campbell, A. H. (1970). Thorax, 25, 178

\title{
Cancer of the Bladder in Patients treated with Chlornaphazine
}

\author{
BENEDICTE LAURSEN, ${ }^{*}$ M.B.
}

\begin{abstract}
Cummary: Two patients treated for Hodgkin's disease with chlornaphazine developed cancer of the bladder five and six years after treatment with the drug had been stopped.
\end{abstract}

\section{Introduction}

The carcinogenic effect of 2-naphthylamine metabolites on the urinary bladder is well documented (Bonser et al., 1952; Scott and Boyd, 1953; Boyland and Manson, 1955).

Chlornaphazine, a derivative of 2-naphthylamine, has previously been used in the treatment of polycythaemia and Hodgkin's disease. Increased incidence of bladder cancer was observed in patients with polycythaemia treated with chlornaphazine as compared with patients who did not receive such treatment (Thiede et al., 1964). Similarly, cancer of the urinary bladder developed in some cases of Hodgkin's disease during treatment with chlornaphazine (Videbæk, 1964). Because of this the drug was withdrawn, at least in Denmark.

The present communication describes two cases of cancer of the urinary bladder occurring five and six years after chlornaphazine treatment was stopped.

\section{Case 1}

The patient was a woman aged 40. In 1957 Hodgkin's disease was diagnosed by biopsy from enlarged cervical glands, afterwards treated with $x$-ray irradiation. From 1959 to 1965 the pelvic lymph nodes became enlarged on four occasions, treated each time with $x$-ray irradiation (total dose 5,590 r). In 1968 lymphangiography showed enlargement of the para-aortic glands and Mobaltron treatment was given. After this there were no signs of activity of Hodgkin's disease.

Anti-neoplastic drugs were given as follows: chlornaphazine in daily doses of $200 \mathrm{mg}$. to a total of about $85 \mathrm{~g}$. from October 1962 to November 1963; cyclophosphamide (Endoxana) 50-100 mg. daily from January 1964 to November 1965; and procarbazine chloride (Natulan) 150-100 mg. daily from May to August 1968. From March 1968 to January 1969 prednisone was added in doses of 5-45 mg. daily.

Bladder Symptoms.-In November 1965, during treatment with cyclophosphamide, the first episode of macroscopic haematuria, severe dysuria, urgency, and frequency occurred. Cystoscopy showed a "chemical cystitis" with mucosal telangiectasias and fibrin deposits, but no proliferative changes. These were - Senior Registrar, Department of Internal Medicine, C, Gentofte Hospital,
Copenhagen, Denmark. interpreted as a cyclophosphamide cystitis, so the drug was discontinued.

In November 1966, June 1968, and November 1968 episodes of gross haematuria occurred with severe pain on micturition. Cystoscopy was performed each time, on the first two occasions showing only slight oedema, fibrin deposits, and mucosal hypertrophy. In November-December 1968 a tumour was seen on the posterior wall of the bladder above the orifice of the right ureter. Urinary sediment contained abnormal cells indicating tumour growth, and biopsy showed a papillomatous bladder carcinoma, grade I, which was treated with electrocoagulation. In January 1969 the patient died of bronchopneumonia with septicaemia after several severe haemorrhages from the bladder resistant to irrigational and other therapy.

Necropsy.-Macroscopic tumour was not found in the urinary bladder. In the right pelvis and upper part of the right ureter several flat mucosal haemorrhages $5-10 \mathrm{~mm}$. in diameter were seen. The mucosa of the trigonum and posterior wall of the bladder was granulated and covered with yellow incrustations and fibrin deposits. Histology showed no changes. In the pre-aortic glands and spleen changes typical of Hodgkin's disease were seen. No changes were found in the thoracic glands. Bronchopneumonia was found in the right lung.

Laboratory Tests. - The most important were blood platelet counts from 10,000 to $40,000 / \mathrm{cu}$. mm.; coagulation tests (recalcification time, Quick time, thrombin time, partial thromboplastin time, factor X, factor V, prothrombin (factor II + factor VII)), no significant changes; serum creatinine $1 \mathrm{mg} . / 100 \mathrm{ml}$.

\section{Case 2}

This patient was a 68-year-old woman. In 1927 enlargement of the cervical glands of unknown aetiology was treated with local injections, ultraviolet light, and $x$-ray irradiation. In 1943 hysterectomy was performed because of profuse and irregular uterine bleedings.

Hodgkin's disease was diagnosed in 1959 by biopsy from an enlarged left supraclavicular lymph node. From November 1962 to May 1967 the disease gradually spread to the right supraclavicular, right axillary, and left axillary nodes, showing varying degrees of nodular enlargement. In May 1967 hilar enlargement was found, and from December 1967 there was infiltration in both lung apices with accompanying cough and exertional dyspnoea. In December 1968 a cavity developed in the left apex. Neither tumour cells nor tubercle bacilli were found. In September 1969 another infiltration occurred near the left pulmonary hilus.

Radiation therapy was given in two series: in September 1967 Mobaltron on the neck, axillae, supraclavicular regions, and the mediastinum (total dose $400 \mathrm{r}$ ); in November 1969 conventional $x$-ray irradiation on the central infiltration (total dose 5,200 r). 
Antineoplastic drugs were given as follows: chlornaphazine 300 mg. daily to a total dose of about $78 \mathrm{~g}$. from February to October 1963; cyclophosphamide $100-150 \mathrm{mg}$. daily from March 1964 to September 1966, from December 1966 to April 1967, and from October 1968 to November 1969; and nitrogen mustard 4 mg./dose, total dosage $24 \mathrm{mg}$., in November 1969. From October 1968 to October 1969 prednisone $10-7.5 \mathrm{mg}$. was given daily.

Bladder Symptoms. - In 1968 the patient had cystitis twice, but without haematuria. In September 1969 macroscopic haematuria developed. After this and until her death she had persistent haematuria with periods of massive bleeding, severe dysuria, urgency, and frequency.

Indirect pyelography in September 1969 raised suspicion of a tumour of the right kidney, but this diagnosis could not be confirmed by renal arteriography and ultrasonic scanning. Cvstoscopy on three occasions showed no localized tumour. Numerous petechiae were seen as well as a granulated area behind the orifice of the right ureter.

In November 1969 urinary sediment contained numerous tumour cells corresponding to a grade III carcinoma-in-situ. Bladder biopsies in December 1969 showed atypical epithelium, urothelium corresponding to a grade III carcinoma, but without invasive growth.

After bladder biopsies and electrocoagulation massive haemorrhage developed, which was resistant to irrigational therapy, transfusions, and aminocaproic acid. The patient died with rapidly decreasing kidney function.

Necropsy. - The kidneys and the urinary bladder were without macroscopic changes. Both pelves showed acute and chronic inflammation. Both lungs were covered with fibrous visceral pleurae. A tumour measuring 7 by $5 \mathrm{~cm}$. involved most of the upper right lobe, and histological examination showed changes typical of Hodgkin's disease. The spleen had foci of extramedullary haematopoiesis, but no changes compatible with Hodgkin's disease.

Laboratory Tests.-Blood platelet counts 250.000, 20,000, $98,000 / \mathrm{cu}$. mm.; coagulation tests as in Case 1 normal; serum creatinine $0.9-5.4 \mathrm{mg} . / 100 \mathrm{ml}$.

\section{Comment}

Previously described cases of cancer of the urinary bladder induced by chlornaphazine were observed after treatment for $2 \frac{1}{2}$ to 10 years and after total dosages of $100 \mathrm{~g}$. or more (Thiede et al., 1964; Videbæk, 1964).

In the present cases the total doses of chlornaphazine were only 78 and 85 g., and five and six years elapsed between discontinuing the drug and the development of bladder cancer. It might therefore be suggested that the bladder malignancies were caused by some other treatment. It is well known that cyclophosphamide can induce a haemorrhagic cystitis with macroscopic changes of the bladder mucosa (Philips, et al., 1961; Gellman et al., 1969), but, to my knowledge, malignant changes have not been described during such treatment, and procarbazine chloride does not produce bladder symptoms. On the other hand, from industrial cancers of the urinary bladder it is known that the time for tumour induction after exposure to the carcinogen is highly variable (Conolly and White, 1969). Consequently, chlornaphazine is thought to be the most likely cause of bladder cancer in the above cases.

REFERENCES

Bonser, G. M., Clayson, D. B., Jull, J. W., and Pyrah, L. N. (1952). British Fournal of Cancer, 6, 412.

Boyland, E., and Manson, D. (1955). Biochemical fournal, 60, ii.

Conolly, J. G., and White, E. P. (1969). Canadian Medical Association Fournal, 100, 879 .

Gellournal, 10 (1969). Fournal of the Canadian Association of Radiologists, 20, 99.

Philips, F. S., Sternberg, S. S., Cronin, Alice P., and Vidal, P. M. (1961). Cancer Research, 21, 1577.

Scott, W. W., and Boyd, H. L. (1953). Fournal of Urology, 70, 914.

Thiede, T., Chievitz, Eva, and Christensen, B. C. (1964). Acta Medica Scandinavica, 175, 721

Videbæk, Aa. (1964). Acta Medica Scandinavica, 176, 45.

\section{Preliminary Communications}

\section{Development of Vascular Lesions in Insulin-treated Animals Fed a Normal Diet}

British Medical Yournal, 1970, 3, 685-687

Sumar mmary: Experiments were undertaken to study the role of hyperinsulinism in the pathogenesis of atheroma. Chickens injected with long-acting insulin for 19 weeks developed lipid containing lesions in their aortas. This provides further evidence in favour of the hypothesis that insulin and atheroma are causally related.

\section{INTRODUCTION}

Abnormalities of lipid and carbohydrate metabolism are commonly found in patients with atherosclerotic vascular disease. Hyperglycaemia, hypercholesterolaemia, and hypertriglyceridaemia have all been reported in this condition. More recently abnormalities in insulin secretion have also been described in patients with ischaemic heart disease. These abnormalities consist of raised insulin responses to oral carbohydrate with or without high fasting plasma insulin levels, and are found in atherosclerotic subjects who are neither obese nor hyperglycaemic (Nikkilä et d., 1965; Peters and Hales, 1965; Christiansen et al., 1968; Tzagournis et al., 1968). It has been suggested that hyperinsulinism may be the common factor linking atherosclerosis with diabetes, obesity, and hyperlipidaemia (Stout and Vallance-Owen, 1969).

As lipid is a major component of the atherosclerotic plaque, and insulin stimulates lipid synthesis elsewhere in the body (Renold et al., 1965), it seemed reasonable to postulate that insulin may have a causal role in atherogenesis. An acute effect of insulin on the lipid metabolism of the arterial wall has been described (Mahler, 1966; Stout, 1968, 1969). It is the accumulation of lipid in the arterial wall over a long period of time, however, that is a feature of atherosclerosis. The effect of long-term administration of insulin on the arteries of experimental animals was therefore investigated.

\section{METHOD}

Of all animals, birds have arteriosclerosis most closely resembling human arteriosclerosis (Dauber, 1944), and the chicken, which like man is omnivorous, has been extensively used for experiments on atherogenesis (Katz and Stamler, 1953). Thirty chickens of the AA hybrid variety, aged 12 weeks, were divided into two groups, each containing 11 females and four males. They were identified by coloured rings, but were otherwise not segregated in any way. They were all housed in one room and fed on commercial chicken feed from one chicken feeder.

One group was injected intramuscularly into the pectoral muscles with insulin zinc suspension. Initially the dose was 10 units daily, but after four weeks it was reduced to 40 units 